\title{
Development of Tetrahydrofuran/Water Optical Waveguide and Its Application to the Observation of Extraction Behavior of 1-Anilino-8-naphtalene Sulfonate at the Tetrahydrofuran/Water Interface
}

\author{
Hiromi TAKIGUChI, ${ }^{* 1}$ Soto Asanuma, $* 2$ Junya KamiYama, ${ }^{* 2}$ Hiroyasu Murata, *2 Yuki HaSEGawa, *2 \\ Satoshi YoshIZAWA, ${ }^{* 2}$ Hiroki HotTA, ${ }^{* 3}$ Tamao ODAKE, ${ }^{* 1}$ Tomonari Umemura, ${ }^{* 4}$ Kiichi SATO, ${ }^{* 2}$ and \\ Kin-ichi TsunODA $* 2 \dagger$ \\ *1 Graduate School of Engineering, The University of Tokyo, 7-3-1 Hongo, Bunkyo, Tokyo 113-8656, Japan \\ *2 Department of Chemistry and Chemical Biology, Gunma University, 1-5-1 Tenjin-cho, Kiryu 376-8515, Japan \\ *3 Graduate School of Maritime Sciences, Kobe University, 5-1-1 Fukae-minamimachi, Higashinada, \\ Kobe 658-0022, Japan \\ *4 School of Life Sciences, Tokyo University of Pharmacy and Life Sciences, 1432-1 Horinouchi, \\ Hachioji 192-0392, Japan
}

\begin{abstract}
A stable two-phase sheath flow using tetrahydrofuran (THF) for an inner flow and water for an outer flow was formed in a glass capillary, and worked as a stable liquid-core/liquid-cladding optical waveguide (THF/water LLW). Although THF and water were miscible with any ratio, the length of the stable THF/water LLW at $0.9-2.1 \mathrm{~cm} \mathrm{~s}^{-1}$ reached at least $150 \mathrm{~mm}$. The THF/water LLW was applied to the observation of extraction behavior of solvatochromic fluorescence dye, 1-anilino-8-naphtalene sulfonate (ANS), through the THF/water interface. ANS was added to the water phase (clad solution) and its fluorescence, which was excited with the guided light $(355 \mathrm{~nm})$ through the LLW, was observed by changing the position of the detector. While the ANS stayed in the region of $70 \%$ THF to the end of the LLW without the addition of cationic surfactant, hexadecyltrimethylammonium ion $\left(\mathrm{CTA}^{+}\right)$at $\mathrm{pH} 3$ and 11, the ion-pair of ANS and $\mathrm{CTA}^{+}$was extracted into the higher concentration region of THF with the addition of $\mathrm{CTA}^{+}$at $\mathrm{pH} 11$.
\end{abstract}

Keywords Liquid-core/liquid-cladding optical waveguide, two-phase sheath flow, fluorescence, tetrahydrofuran, 1-anilino8-naphtalene sulfonate, hexadecyltrimethylammonium ion, ion pair

(Received January 15, 2017; Accepted February 22, 2017; Published April 10, 2017)

\section{Introduction}

Various types of optical waveguides have been applied to analytical chemistry. Liquid core waveguides (LCWs), i.e., liquid-core/solid-cladding waveguides, are commonly used for the enhancement of the sensitivities of spectroscopic measurements such as spectrophotometry, ${ }^{1-3}$ fluorometry, ${ }^{4}$ and Raman spectroscopy. ${ }^{5}$ Moreover, various types of solid-core/ liquid-cladding or solid-core/gas-cladding waveguides have also been used for highly sensitive chemical sensing and spectroscopic study of solid/liquid or solid/gas interfaces. Integrated optical waveguides of planar type have most widely been applied for these purposes. ${ }^{6-8}$

Besides those waveguides, liquid/liquid optical waveguides (LLWs), which have a liquid-core/liquid-cladding structure, have firstly been proposed by our group. ${ }^{9-13}$ LLWs have been formed with sheath flow of liquids from concentric glass capillaries into an outer glass capillary. Both immiscible solvent

$\dagger$ To whom correspondence should be addressed.

E-mail: tsunoda@gunma-u.ac.jp systems (e.g., toluene/water, diethyl ether/water) and miscible solvent systems (e.g., tetrahydrofuran (THF)/water, sodium chloride solution/water) can be used to form the LLWs. We have been trying to use these LLWs as new tools for studying the liquid/liquid interfaces. ${ }^{10-13}$ The concept of LLW, on the other hand, has recently been extended to the microchip fields, and it has become one of the key elements in the new field of "optofluidics," where it is applied to manipulate light in micro-chips, e.g., as an optical switch and an evanescent coupler. ${ }^{14-21}$

Chemical reactions and mass-transfer phenomena at the liquid/liquid interface have attracted much attention of researchers of various fields, such as separation chemistry, organic syntheses and biology. Although various methods, i.e., electrochemical methods, total internal reflection spectroscopy such as fluorescence spectroscopy (TIRF), Raman spectroscopy, second harmonic generation (SHG) spectroscopy, the time-resolved quasi-elastic laser scattering (QELS) method and so on, ${ }^{22-25}$ have been applied to this subject, they are difficult to be applied to measure the transient behavior of the reactions at the interface, and have mainly been used to study phenomena in equilibrium states or slow reaction processes at static 
liquid/liquid interfaces. To monitor reactions at a dynamic interface, the use of a two-phase flow system, in which the stable liquid/liquid interface is formed, may be one of the important approaches. Tokimoto et al. studied the kinetic process of metal-complexation at liquid/liquid interfaces using a two-phase sheath flow, where a laser induced fluorescence measurement system with the confocal microscopy system was applied. ${ }^{26,27}$ Although the method has been found to be useful for the kinetic studies of the interfacial reactions, it is not strictly surface-selective. Thus, we have used this sheath flow as an LLW to measure the interfacial phenomena with high sensitivity by the evanescent wave of guiding light, i.e., by TIRF spectrometry. In our previous papers, we preliminarily demonstrated that LLWs are applicable to both miscible and immiscible liquid/liquid interfaces and can be used to monitor the fluorescence of molecules at the interface.9,10 The formation conditions of LLWs with both miscible and immiscible solvent systems were discussed and the behavior of rhodamine B and 1-anilino-8-naphtalene sulfonate (ANS), which is known as a solvatochromic fluorophore, at the interface was observed particularly with the immiscible LLWs. ${ }^{11}$ Moreover, the absorbance measurements of the LLWs were also applied to detect non-fluorescent molecules at the interface. ${ }^{10}$

Although the interfaces between immiscible solvents have been relatively well defined and studied intensively, very few studies have been done on the mass transfer and the chemical reactions at the interface between miscible solvents in spite of their importance in chemistry and biology, mainly because of the lack of experimental techniques. For example, Tabata et al. reported that the mixture of acetonitrile and water in capillary tubing can be used for chemical separation based on the difference in the distribution of analytes to acetonitrile clusters in the mixture. ${ }^{28}$ Their studies may suggest the importance of the mass transfer at the interfaces between the miscible solvents in separation science. Moreover, the interfaces may also be important in synthetic chemistry to control chemical reactions and to develop the new synthetic procedures. ${ }^{29}$ Recently, micro-fluidic techniques have been developed rapidly and applied to produce the dynamic interfaces between miscible solvents in integrated lab-on chips. They have been applied to study the mass transfer and the chemical reactions at the interfaces between both immiscible and miscible solvent systems. ${ }^{30,31}$ The LLW with a miscible solvent system, on the other hand, can provide an alternative way to study these subjects. Our LLWs using sheath flow in capillary tubing have the following useful properties. (i) The interface could be defined by its waveguide structure and the interface selective spectroscopic measurements can be performed, although their position selectivity may be worse than the LLW with an immiscible solvents system because of the nature of the graded refractive index in the LLW with a miscible solvents system: (ii) the length of the interface as well as the period of the interface lasting can be changed more flexibly than the chip technique (e.g., the length of the LLW was extended to $150 \mathrm{~mm}$ in this work (see below) ):(iii) the greater specific interfacial area to the inner flow (the core) can easily be achieved: (iv) the LLW is easier and less expensive to build.

In this work, the characteristics of the LLW with the THF/ water system as a new tool for studying dynamic interfaces between various solvent systems were investigated where the ion-pair extraction of 1-anilino-8-naphtalene sulfonate (ANS) and hexadecyltrimethylammonium ion $\left(\mathrm{CTA}^{+}\right)$from the water phase to the THF phase and the behaviors of the ion-pair in the LLW were studied as an example.

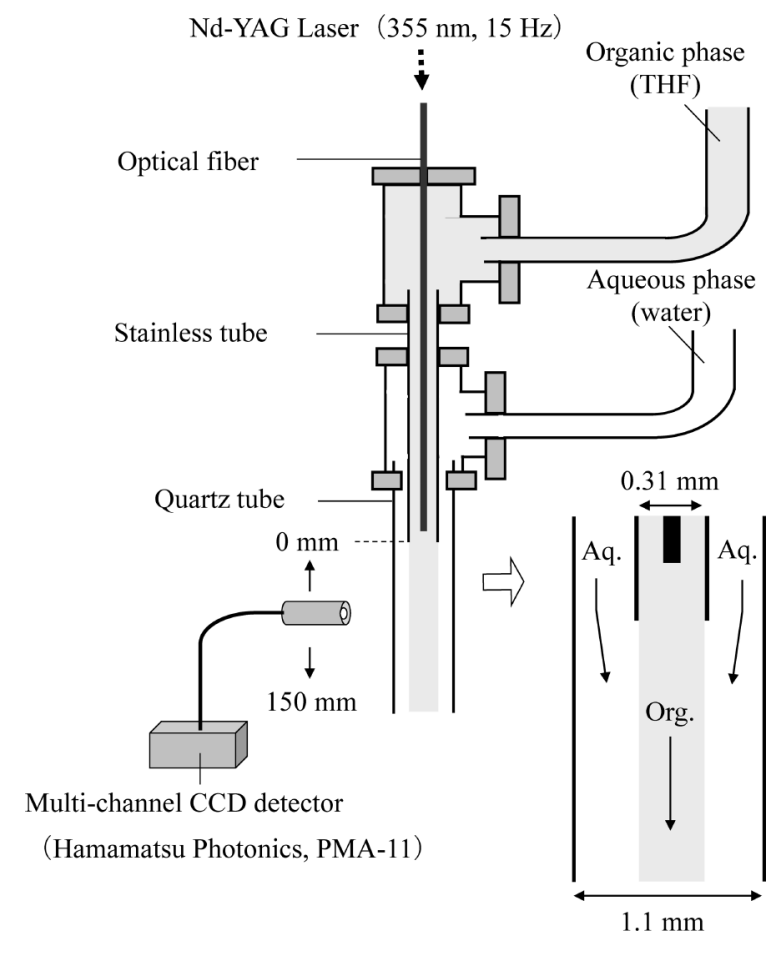

Fig. 1 THF/water liquid/liquid optical waveguide setup (THF/water LLW). The outer capillary was $1.1 \mathrm{~mm}$ i.d. and the inner capillary was $0.31 \mathrm{~mm}$ i.d. and $0.51 \mathrm{~mm}$ o.d. The aqueous and THF phases were driven by hydrostatic pressure produced from the difference in the height from the end of the outer quartz tube to the liquid level of each phase, respectively. The optical probe connected to the multi-channel CCD detector moved along the outer quartz tube for $150 \mathrm{~mm}$.

\section{Experimental}

\section{Reagents and chemicals}

1-Anilino-8-naphtalene sulfonate (ANS, ICN Biochemical Inc., USA), as a fluorescent probe, was used without further purification. Hexadecyltrimethylammonium bromide (cetyltrimethylammonium bromide, $\mathrm{CTAB}$ ), $\mathrm{NaH}_{2} \mathrm{PO}_{4} \quad \mathrm{KH}_{2} \mathrm{PO}_{4}$, $\mathrm{Na}_{2} \mathrm{~B}_{4} \mathrm{O}_{7}$, and $\mathrm{Na}_{2} \mathrm{CO}_{3}$ were used as received from Wako Pure Chemical Industries, Japan. Tetrahydrofuran (THF) (95\%) was purchased from Wako Pure Chemical Industries, Japan. All of the aqueous solutions were prepared with water purified by a Milli-QII system (Millipore, USA).

The ANS $\left(0.75 \times 10^{-3} \mathrm{~mol} \mathrm{dm}^{-3}\right)$ and CTAB $\left(3.29 \times 10^{-4} \mathrm{~mol}\right.$ $\mathrm{dm}^{-3}$ ) stock solutions were prepared by dissolving them in water. The $\mathrm{pH}$ values of the aqueous solutions were adjusted with $\mathrm{NaH}_{2} \mathrm{PO}_{4} / \mathrm{H}_{3} \mathrm{PO}_{4}(\mathrm{pH} 3.0), \mathrm{KH}_{2} \mathrm{PO}_{4} / \mathrm{Na}_{2} \mathrm{~B}_{4} \mathrm{O}_{7}(\mathrm{pH}$ 7.0), or $\mathrm{Na}_{2} \mathrm{~B}_{4} \mathrm{O}_{7} / \mathrm{Na}_{2} \mathrm{CO}_{3}$ ( $\mathrm{pH}$ 11.0) buffers. Moreover, the ionic strength of all the aqueous solutions was adjusted to $0.1 \mathrm{~mol} \mathrm{dm}^{-3}$ by adding sodium chloride.

\section{Apparatus}

The experimental set up of an LLW for the miscible solvent system as well as a photo of the typical THF/water LLW are shown in Fig. 1 and Fig. S1 (Supporting Information), respectively. In the previous paper, the LLW for the immiscible system was described. ${ }^{9,10}$ There is a prime difference between the previous system and the present system for the miscible solvent system. That is, the direction of the flow of the present system was downward, while that of the previous system was upward. In the previous system, the droplet formation of the 
<smiles>O=S(=O)(O)c1cccc2cccc(Nc3ccccc3)c12</smiles>

Scheme 1 8-Anilino-1-naphtalene sulfonic acid (ANS).

organic solvent occurred at the end of the LLW, and the droplets interfered with the LLW when the flow was downward, because the density of the droplet is lower than that of water and the droplets always moved upwards. On the other hand, no droplet formation occurred in the present system, thus, the LLW of the downward flow was more convenient for the spectroscopic measurements (see the following chapter). The outer capillary was a quartz tube $(1.1 \mathrm{~mm}$ i.d., $150 \mathrm{~mm}$ long) and the inner capillary was a stainless tube $(0.31 \mathrm{~mm}$ i.d., $0.51 \mathrm{~mm}$ o.d., and $100 \mathrm{~mm}$ long). The outer and the inner capillaries were assembled with T-joints, and the inner capillary was partially inserted into the outer capillary as shown in Fig. 1 . THF $\left(n_{\mathrm{D}}=\right.$ 1.41) flowed into the inner capillary as the organic phase, while water $\left(n_{\mathrm{D}}=1.33\right)$ flowed into the outer capillary as the aqueous phase. An optical fiber (SF-112, Sumita Optical Grass, Inc., Japan, $0.175 \mathrm{~mm}$ o.d., UV transmitted, NA $=0.20$ ) was inserted into the inner capillary. The source light, which was provided by a Nd-YAG laser (Minilite II, $15 \mathrm{~Hz}, 355 \mathrm{~nm}, 4 \mathrm{~mJ}$, Continuum, USA), was introduced into the inner flow through the optical fiber. Fluorescence signals and scattering lights from the LLW were collected through the quartz optical fiber (core $0.4 \mathrm{~mm}$, NA 0.21 ), which was placed as close to the surface of the outer capillary as possible and was moved from the tip of the inner capillary to the end of the LLW along with the outer capillary. Then, the light signals were sent to a multichannel CCD detector (PMA-11, Hamamatsu Photonics Co., Japan) and spectra of $350-700 \mathrm{~nm}$ were obtained. Two syringe pumps were first used to send the THF and water to the LLW. However, as they brought considerable pulsed noises to the measurements, the gravity-driven method was applied to send the solutions where their flow rates were adjusted by changing the levels of their surfaces in the reservoirs.

\section{Measurement}

Formation conditions of stable THF/water LLW. We defined the THF/water LLW as stable, when the minimum scattering light was observed. The flow rate of THF was ca. 0.04 to $0.095 \mathrm{~cm}^{3} \mathrm{~min}^{-1}$, while the flow rate of water was $c a .0 .4$ to $1.23 \mathrm{~cm}^{3} \mathrm{~min}$. The ratio of the aqueous phase flow rate to organic phase was fixed at $c a$. 11.3 where the linear velocities of water and THF are almost the same (Fig. 2).

Characteristics of ANS as a solvatochromic fluorophore. 1-Anilino-8-naphtalene sulfonate (ANS) (Scheme 1) is wellknown as a solvatochromic fluorophore; the strong blue shift of the fluorescence spectrum and the increase in its intensity are observed along with the increase in the hydrophobicity of the solvent surrounding the ANS molecules. Thus, the fluorescence spectrum of ANS was used as a measure of the hydrophobicity of the THF/water interface where ANS molecules gave the fluorescence. Figure S2 (Supporting Information) shows the ANS fluorescence spectra obtained in various solvent conditions by a conventional fluorospectrometer. As shown in the figure, the $\lambda_{\max }$ of the ANS fluorescence spectrum is changed from $524 \mathrm{~nm}$ at water to $475 \mathrm{~nm}$ at $95 \%$ THF. Moreover, the ion-pair extraction behavior of ANS and hexadecyltrimethylammonium ion $\left(\mathrm{CTA}^{+}\right)$at the toluene/water interface was observed by total internal reflection fluorometry (TIRF) using the conventional fluorospectrometer as following the method of Watarai et al. ${ }^{22}$ At $\mathrm{pH} 3$ and 7 of the water phase, no ion-pair extraction of ANS and $\mathrm{CTA}^{+}$was observed, while the ion-pair was quickly extracted into toluene at $\mathrm{pH} 11$. As ANS has both secondary amine $\left(\mathrm{p} K_{\mathrm{a}}=5.6\right)^{32}$ and sulfonate groups, it forms zwitter-ion in the lower $\mathrm{pH}$ region, while it becomes anion in the higher $\mathrm{pH}$ region. Thus, the ion-pair formation of ANS and $\mathrm{CTA}^{+}$occurs only in the higher $\mathrm{pH}$ region. Based on such preliminary experiments, the ion-pair extraction of ANS and $\mathrm{CTA}^{+}$was studied with the THF/water LLW where the $\mathrm{pH}$ of the aqueous phase was set at 11. Moreover, the effects of $\mathrm{CTA}^{+}$on the ANS fluorescence spectrum in the THF-water mixture were investigated with the conventional fluorospectrometer as shown in Fig. S2. Although the blue shift of the ANS spectrum was observed with the addition of $\mathrm{CTA}^{+}\left(10 \mu \mathrm{mol} \mathrm{dm}{ }^{-3}\right)$ in pure water, there is almost no change in the spectrum observed in the mixture of THF and water.

Observation of ion-pair extraction of ANS and $\mathrm{CTA}^{+}$with the THF/water LLW. The aqueous samples ( $\mathrm{pH} 11)$ which contain $10 \mu \mathrm{mol} \mathrm{dm}{ }^{-3}$ of ANS and $10 \mu \mathrm{mol} \mathrm{dm}{ }^{-3}$ of $\mathrm{CTA}^{+}$were let to stand for one night to make sure of the formation of the ion-pair, and were sent to the LLW to measure the fluorescence spectra of ANS and the results were compared with those of the samples with different $\mathrm{pH}$, and/or do not contain $\mathrm{CTA}^{+}$.

\section{Computational fluid dynamics (CFD) simulation of THF/water LLW}

The waveguide structures of the LLW, i.e., the distribution of THF concentration and the velocity distribution of the flow in the LLW, were predicted using CFD. The CFD software, COMSOL Multiphysics $^{\oplus}$ (COMSOL Inc., USA), which is based on a finite-volume method, was used. To describe the mixing of the core and cladding liquids, a three-dimensional Navier-Stokes equation and a convection-diffusion equation based on Fick's law with laminar flow under steady state were chosen. The basic way of CFD simulation was almost the same as that described in our previous paper, ${ }^{13}$ except that the different software (STAR $\mathrm{CD}^{\odot}$ ) was used. The diffusion coefficient of THF-water mixture in water is known to change considerably, depending on its concentration in the range from $c a .2 \times 10^{-10}$ to $4 \times 10^{-9} \mathrm{~m}^{2} \mathrm{~s}^{-1} .{ }^{33}$ Thus, the following approximation equation, based on the values of Ref. 33, was used for the calculation.

$$
\begin{gathered}
\log D_{\mathrm{THF}}=4.394 \times 10^{-6} c^{3}-2.788 \times 10^{-4} c^{2}- \\
1.095 \times 10^{-2} c-8.962
\end{gathered}
$$

Where $D_{\mathrm{THF}}$ is the diffusion coefficient of the THF-water mixture in water and $c$ is the percent concentration of THF in the THF-water mixture. The dimensions of the LLW used for the simulation were the same as those for the experiments. The details of the CFD simulation will be published elsewhere.

\section{Results and Discussion}

\section{Characteristics of the THF/water LLW}

Optimization of the flow conditions. The stability of the THF/water LLW was evaluated in terms of the intensity of the scattering light emitted from the LLW, as the instability of the LLW, i.e., the visible swing and/or pulsed disturbance of the 


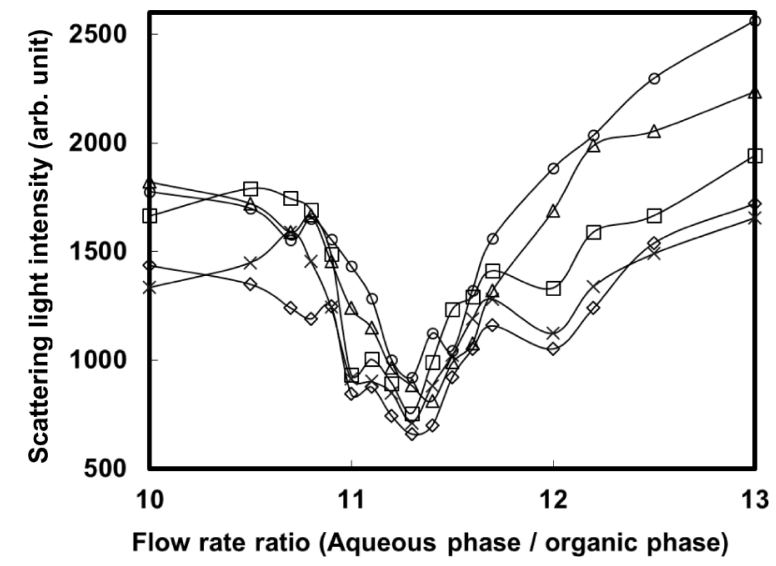

Fig. 2 Dependence of the scattering light intensity $(355 \mathrm{~nm})$ upon the ratio of the aqueous phase flow rate to the THF phase flow rate at various linear velocities of the THF phase. The organic phase was THF that was flowed at a fixed linear velocity $(\diamond, 0.9 ; \times, 1.1 ; \square, 1.5$; $\left.\triangle, 1.9 ; \bigcirc, 2.1 \mathrm{~cm} \mathrm{~s}^{-1}\right)$. The aqueous phase was water, and the ratio of the flow rate was varied from 10 to 13 to the THF phase.

flow resulted in the stronger scattering light. We noticed that such swing and pulsed disturbance of the flow, which were particularly serious at a lower flow rate, were mainly generated by the syringe pumps. Thus, to overcome these problems, we used the gravity-driven method to send aqueous and organic phases. This method made it possible to form much more stable THF/water LLW as shown in Fig. S1 (Supporting Information). Figure 2 shows the dependence of the intensity of the scattering light $(355 \mathrm{~nm})$ upon the ratio of the aqueous phase flow (clad) rate to the organic phase flow (core) rate at various linear velocities of the organic phase (at the tip of the inner capillary (calculated values)). In the region of $0.9-2.1 \mathrm{~cm} \mathrm{~s}^{-1}$ of the linear velocity of the organic phase $\left(0.04-0.095 \mathrm{~cm}^{3} \mathrm{~min}^{-1}\right)$, the visually stable sheath flow was formed, and the scattering light intensity was monitored by changing the flow rate of the aqueous phase, i.e., the ratio (10 to 13), as shown in Fig. 2. The intensity of the scattering light was the minimum at $c a .11 .3$ of the ratio where the linear velocities of water and THF phases, i.e., the average linear velocity of the core and clad solutions, were almost the same. Thus, this ratio was maintained throughout this study unless otherwise stated.

Reynolds number (Re) of the flow at the optimum condition. The Reynolds number ( $\mathrm{Re})$ is an important parameter in viscous flow to decide the state of the flow. Re is defined by

$$
\operatorname{Re}=\frac{\rho V D}{\mu}
$$

where $\rho, \mu, V$ and $D$ stand for the fluidic density, viscosity, characteristic velocity and characteristic length, respectively. In the case of the LLW, we regarded the linear velocity as $V$, the i.d. of the inner capillary as $D$ for the organic phase, and the difference between the i.d.s of the inner and outer capillaries as $D$ for the aqueous phase. The fluidic viscosity and density for THF are $0.46 \mathrm{mPa} \cdot \mathrm{s}$ and $0.89 \mathrm{~kg} \mathrm{~m}^{-3}$, and those for water are $0.95 \mathrm{mPa} \cdot \mathrm{s}$ and $1.00 \mathrm{~kg} \mathrm{~m}^{-3}$, respectively. In general, a flow with a higher value of the Re number becomes turbulent flow, and one with a lower value becomes laminar flow. In the LLW for the immiscible two-phase flow system, however, as the inertial force has to exceed the viscous drag to achieve laminar flow, relatively greater value of Re was necessary to form the

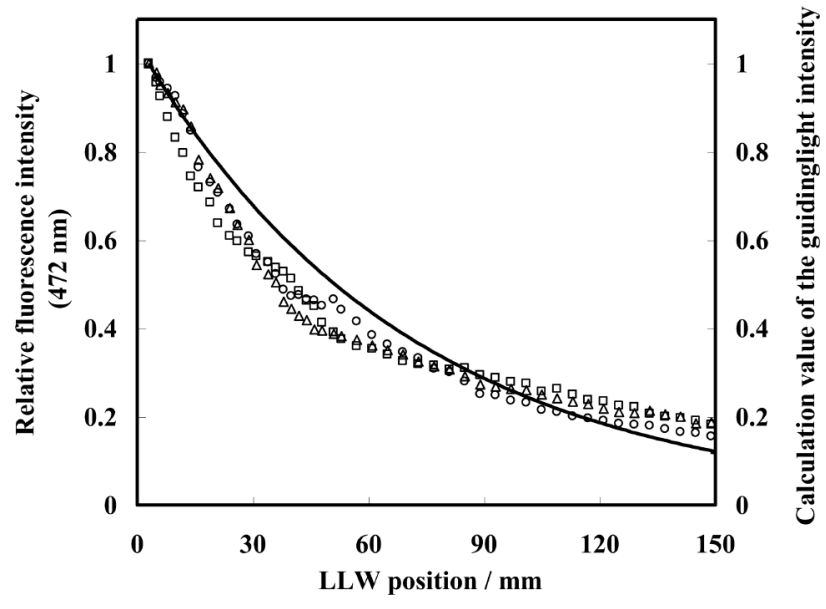

Fig. 3 Attenuation of the guided light (the average linear velocity of the core and the clad solutions; $\triangle, 1.1 ; \square, 1.5 ; \bigcirc, 2.1 \mathrm{~cm} \mathrm{~s}^{-1}$ ). The ratio of the aqueous phase flow rate to the THF phase flow rate was kept at 11.3. The intensity of the guided light was monitored as the fluorescence intensity of ANS contained in the THF (core) solution. The THF phase contained $20 \mu \mathrm{mol} \mathrm{dm}{ }^{-3}$ of ANS and the solid line shows the theoretical attenuation line, in which only the absorption due to ANS was taken into account.

LLW; when the viscous drag becomes dominant, the formation of droplets occurs and laminar flow cannot be maintained. ${ }^{10}$ For the LLW of the miscible two-phase flow system such as the THF/water LLW, on the other hand, droplet formation does not occur, thus, the two-phase flow in the LLW apparatus can be regarded as general viscous fluidics in terms of hydrodynamics. The region of Re where the THF/water LLW was formed was ca. 5.4 to $12.6\left(0.9-2.1 \mathrm{~cm} \mathrm{~s}^{-1}\right)$ for the organic phase, when the Re for the aqueous phase is $c a$. 7.5 to $17.5\left(0.9-2.1 \mathrm{~cm} \mathrm{~s}^{-1}\right)$. The Re values for the THF/water LLW were much smaller than those for immiscible systems.

Attenuation of the guided light. To evaluate the LLW as a light guide, first, we tried to monitor the scattering light from the LLW. However, a small portion of the source light, which leaked from the core in the upstream region of 0 to $13 \mathrm{~mm}$ from the tip of the inner capillary, entered into the wall of the outer capillary, and it disturbed the measurement of the scattering light from the LLW. Thus, $20 \mu \mathrm{mol} \mathrm{dm}{ }^{-3}$ of ANS THF solution was used as an inner flow, and the fluorescence intensity of ANS at $472 \mathrm{~nm}$ was measured by changing the measurement position from the tip of the inner capillary to the end of the outer capillary. Then, as shown in Fig. 3, the attenuation curves of the ANS fluorescence were compared with the calculated one where only the attenuation of the guided light due to the absorption of ANS molecules was postulated. As shown in this figure, the experimental curves $(\triangle, \square, \bigcirc)$ and the calculated one (solid line) coincided with one another very well. It means that the attenuation of the guided light in the LLW was the minimum at $355 \mathrm{~nm}$ (less than $c a .10 \%$ at $150 \mathrm{~mm}$ from the tip), when there is no absorbent of the guided light in the LLW other than ANS molecules.

Results of CFD simulation. Figure S3 (Supporting Information) shows the simulated concentration distribution of THF in the LLW at the various distances (distance from the tip of the inner capillary). Results at three different average linear flow rates of THF and aqueous solutions are shown. These figures show that the waveguide structure, i.e., the concentration gradient of THF, was well kept through the whole LLW, and higher than $75 \%$ of 


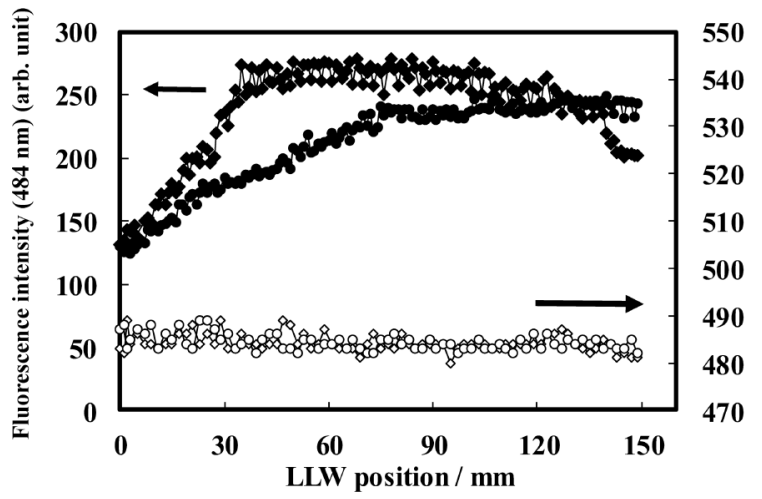

Fig. 4 Fluorescence intensity and the maximum wavelength of the fluorescence spectrum of ANS at $\mathrm{pH} 3$ and 11 of the aqueous phase without the addition of $\mathrm{CTA}^{+}$. (Closed circle, fluorescence intensity; red $\mathrm{pH} 3$, blue $\mathrm{pH} 11$. Open circle, maximum wavelength of the fluorescence; red $\mathrm{pH} 3$, blue $\mathrm{pH}$ 11.) Ten $\mu \mathrm{mol} \mathrm{dm}^{-3}$ of ANS was added to the aqueous phase, the average linear velocity of the core and the clad solutions was $1.1 \mathrm{~cm} \mathrm{~s}^{-1}$, and the ratio of the aqueous phase flow rate to the THF phase flow rate was kept at 11.3.

THF in the center of the core should be maintained even at $150 \mathrm{~mm}$ of the slowest condition $\left(1.1 \mathrm{~cm} \mathrm{~s}^{-1}\right)$. However, a slight discrepancy was observed between this simulation and ANS work (see below).

Observation of ion-pair extraction of ANS and $\mathrm{CTA}^{+}$into the THF-phase

Fluorescence of ANS with the LLW. Figure 4 shows the changes in the intensity and the $\lambda_{\max }$ of ANS fluorescence along with the distance from the tip of the inner capillary of the LLW, when $10 \mu \mathrm{mol} \mathrm{dm}{ }^{-3}$ ANS aqueous solutions at $\mathrm{pH} 3$ and 11 were used as the outer flow of the LLW at $1.1 \mathrm{~cm} \mathrm{~s}^{-1}$ of the average linear velocity of the THF and aqueous phases. The inner flow of LLW was pure THF with no solute. At $\mathrm{pH} \mathrm{3}$, the intensity of the ANS fluorescence gradually increased along with the increase in the distance; that photo was shown in Fig. S5. On the other hand, at pH 11 the intensity increased more steeply, then, became almost constant. That is, the slight difference in the behavior of ANS between $\mathrm{pH} 3$ and 11 was observed, although the reason was not clear at present. The fluorescence spectra of ANS at $\mathrm{pH} 3$ and 11, including the $\lambda_{\max } \mathrm{s}$ as shown in Fig. 4 , were exactly the same and did not change throughout the measurement region. The value of the $\lambda_{\max }(c a .484 \mathrm{~nm})$ corresponds to that in $c a$. $70 \%$ THF. Moreover, Fig. S4 (Supporting Information) shows the ANS spectra obtained with the LLW at pH 3, which were almost the same as that of ANS spectrum at $70 \%$ ANS in Fig. S2, i.e., no broadening of the spectra was observed. These results may mean that the ANS molecules at $c a$. $70 \%$ THF in the mixing layer contribute mostly to the fluorescence spectra.

Moreover, the dependence of the intensity change of the ANS fluorescence upon the measurement position of the LLW from the tip of the inner capillary was monitored, when various average linear velocities of the THF and the aqueous phases were applied. The results at $\mathrm{pH} 11$ are shown in Fig. S6 (Supporting Information) as an example. With the increase in the average linear velocity, the contact time of the core and the clad solutions becomes shorter at the same observing position. Thus, the fluorescence intensity of ANS decreased with the increase in the average linear velocity. That is, the contact time is more essential for the diffusion process of ANS molecules in

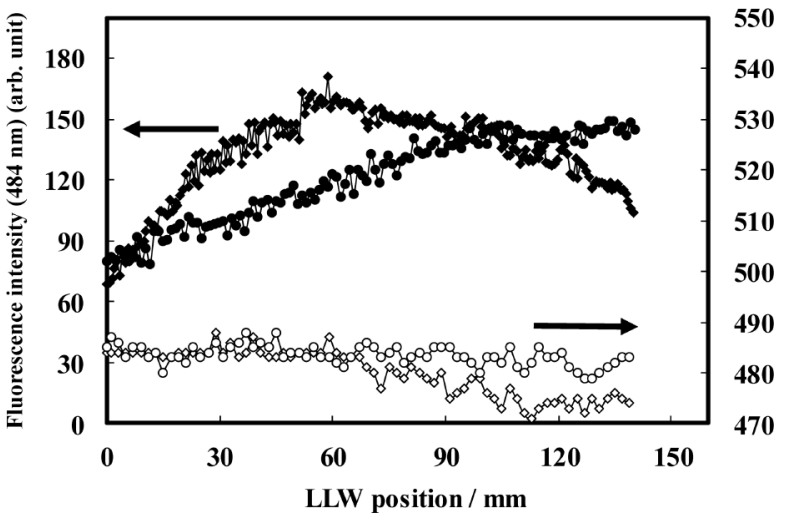

हू

Fig. 5 Fluorescence intensity and the maximum wavelength of the fluorescence spectrum of ANS with the addition of $\mathrm{CTA}^{+}$. (Closed marker, fluorescence intensity; circle $\mathrm{pH} 3$, square $\mathrm{pH} 11$. Open marker, maximum wavelength of the fluorescence; circle $\mathrm{pH} 3$, square $\mathrm{pH}$ 11.) ANS and $\mathrm{CTA}^{+}\left(10 \mu \mathrm{mol} \mathrm{dm}{ }^{-3}\right.$ each) were added to the aqueous phase. Other experimental conditions were the same as those of Fig. 4.

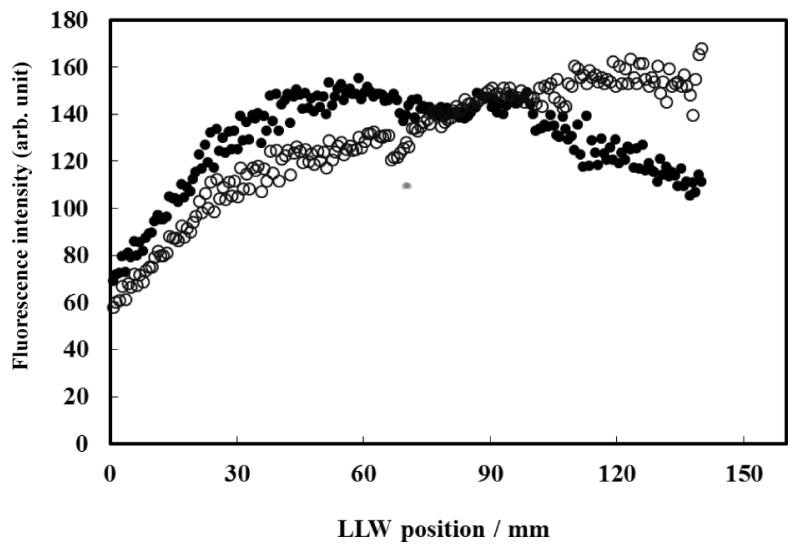

Fig. 6 Fluorescence intensities of ANS at 472 and $484 \mathrm{~nm}$ with the addition of $\mathrm{CTA}^{+}$at $\mathrm{pH}$ 11. (Closed circle, fluorescence intensity at $484 \mathrm{~nm}$. Open circle, fluorescence intensity at $472 \mathrm{~nm}$.) The experimental conditions were the same as those of Fig. 5.

\section{the LLW.}

Effects of the addition of $\mathrm{CTA}^{+}$. As mentioned in the experimental section, the ion-pair formation of ANS and $\mathrm{CTA}^{+}$and its extraction at $\mathrm{pH} 11$ were observed at the toluene/water system. Thus, the aqueous solution containing $10 \mu \mathrm{mol} \mathrm{dm}{ }^{-3}$ of ANS and $\mathrm{CTA}^{+}$at $\mathrm{pH} 11$ was used for the outer flow of the LLW, and the fluorescence spectra of ANS were monitored along with the distance from the tip of the inner capillary of the LLW. The changes in the intensity and the $\lambda_{\max }$ of ANS spectra were shown in Fig. 5 at $\mathrm{pH} 3$ and 11. The data at $\mathrm{pH} 3$ where the ion-pair formation did not occur were also taken for the comparison. At $\mathrm{pH} 3$, almost the same tendency as those without the addition of $\mathrm{CTA}^{+}$in Fig. 4, i.e., the gradual increase in the intensity and no change in the $\lambda_{\max }$, were obtained, though the absolute fluorescence intensity was decreased. On the other hand, the further blue shift of the $\lambda_{\max }$ was clearly observed at $\mathrm{pH} 11$. This situation was shown more clearly in Fig. 6. The fluorescence of ANS at $484 \mathrm{~nm}\left(\lambda_{\max }, c a .70 \%\right.$ THF) increased then turned to decrease at the middle course of the LLW, while that at $472 \mathrm{~nm}\left(\lambda_{\max }, c a .95 \% \mathrm{THF}\right)$ gradually increased and the 
wavelength of $472 \mathrm{~nm}$ became the $\lambda_{\max }$ of the spectra after $c a$. $90 \mathrm{~mm}$ from the tip. This behavior was completely different from that without $\mathrm{CTA}^{+}$at $\mathrm{pH} 11$ as shown in Fig. 4. Moreover, as described in the experimental section, the existence of $\mathrm{CTA}^{+}$ in the bulk solution of the mixture of THF and water did not bring any spectral change of ANS fluorescence as shown in Fig. S2. It means that the ion-pair formation itself does not cause the spectral change of ANS in the THF/water mixture. These facts may suggest that the accelerated diffusion of the ion-pair into the THF phase, which caused the further blue shift of the $\lambda_{\max }$, was observed; the $\lambda_{\max }$ of $472 \mathrm{~nm}$ corresponds to that in $c a .95 \%$ THF. In other words, the extraction process between miscible solvents could be observed using this LLW technique.

Behavior of ANS in LLW. The ANS spectrum in ca. 70\% THF was always obtained with these LLW measurements except for the condition of the addition of $\mathrm{CTA}^{+}$at $\mathrm{pH} 11$. These results may mean that the guided light always reached to the region of ca. $70 \%$ and more than $c a .70 \%$ of THF in the LLW. That is, only the ANS molecules in the region of $c a$. $70 \%$ and more than ca. $70 \%$ of THF were effectively excited with the guided light and emitted the fluorescence. Without the formation of the ion-pair, ANS is not so soluble in THF. Thus, it remained in the region of up to $c a$. $70 \%$ THF, although the accumulation of ANS at the interface was observed as shown in Figs. 4 to 6 as well as Figs. S5 and S6 (Supporting Information).

Comparison between experiments and CFD simulation. As mentioned above, there was a slight discrepancy between the CFD simulation and the ANS work, i.e., the $\lambda_{\max }$ of ANS with the addition of $\mathrm{CTA}^{+}$at $\mathrm{pH} 11$ might suggest that $c a .95 \%$ of the concentration of THF at the center of the LLW at the average linear flow velocity of $1.1 \mathrm{~cm} \mathrm{~s}^{-1}$ was maintained down to $c a$. $150 \mathrm{~mm}$, while the CFD simulation suggested that it would decrease to $c a$. $80 \%$, although it was still quite high. It means that the actual diffusion of THF might be slower than that expected by CFD simulation. Although the reason is unclear at present and we need further studies in both simulation and experiments on the waveguide structure of LLWs to clarify the reason, we consider two possibilities at present as follows. One is due to the uncertainty of $\lambda_{\max }$ measurements of the ANS spectrum because its peak has a rather broad nature, and the intensity at the peak almost does not change in the range of $\pm 5 \mathrm{~nm}$. Thus, we might have overestimated the THF concentration. The other is due to the influence of the surface activity of $\mathrm{CTA}^{+}$with the diffusion of THF, although we do not have any data on this. To any case, the occurrence of further diffusion of the ion pair compared with ANS itself into the core center can be supported by Figs. 5 and 6 .

\section{Conclusions}

The stable THF/water LLW was formed up to $150 \mathrm{~mm}$ long and was applied to the observation of the extraction behavior of ANS through the THF/water interface. From the fluorescence spectral changes of ANS, we concluded that ANS stayed in the region of $70 \%$ THF to the end of the LLW without the addition of $\mathrm{CTA}^{+}$at both $\mathrm{pH} 3$ and 11, while the ion-pair of ANS and $\mathrm{CTA}^{+}$was extracted into the higher concentration region of THF at $\mathrm{pH}$ 11. Although further studies with both experiments and the CFD simulation are necessary to characterize the LLW systems, they could be a new useful tool to observe the interfacial region of the core and the clad solutions, i.e., dynamic phenomena at the interfacial regions of various solvent systems.

\section{Acknowledgements}

This work was supported in part by a Grant-in-Aid for Exploratory Research (No. 16655026) and a Grant-in-Aid for Scientific Research (B) (No. 20350033) for from Japan Society for the Promotion of Science.

\section{Supporting Information}

Photograph of the THF/water LLW (Fig. S1), fluorescence spectra of ANS with and without $\mathrm{CTA}^{+}$in various THF concentrations with conventional fluorometer (Fig. S2), CFD simulation of $\mathrm{THF} /$ water LLW at various average linear velocities of THF and aqueous solutions (Fig. S3), relative fluorescence spectra of ANS $\left(10 \mu \mathrm{mol} \mathrm{dm}{ }^{-3}, \mathrm{pH} 3\right)$ from the THF/water LLW (Fig. S4), photograph of the THF/water LLW with $10 \mu \mathrm{mol} \mathrm{dm}{ }^{-3}$ of ANS in the aqueous phase (pH 3) (Fig. S5), and intensity changes of ANS fluorescence along with the distance of the and observation point from the tip of the inner capillary (Fig. S6) are provided in Supporting Information. This material is available free of charge on the Web at http:// www.jsac.or.jp/analsci.

\section{References}

1. K. Fuwa, L. Wei, and K. Fujiwara, Anal. Chem., 1984, 56, 1640.

2. H. Takiguchi, A. Tsubata, M. Miyata, T. Odake, H. Hotta, T. Umemura, and K. Tsunoda, Anal. Sci., 2006, 22, 1017.

3. J. Ma, P. K. Dasgupta, W. Blackledge, and G. R. Boss, Anal. Chem., 2010, 82, 6244.

4. K. Fujiwara, J. B. Simeonsson, B. W. Smith, and J. D. Winefordner, Anal. Chem., 1988, 60, 1065.

5. J. Stone, Appl. Phys. Lett., 1972, 20, 239.

6. P. L. Edmiston, J. E. Lee, L. L. Wood, and S. S. Saavedra, J. Phys. Chem., 1996, 100, 775.

7. T. Umemura, H. Hotta, T. Abe, Y. Takahashi, H. Takiguchi, M. Uehara, T. Odake, and K. Tsunoda, Anal. Chem., 2006, $78,7511$.

8. H. Hotta, K. Tatsuno, Y. Hattori, T. Hashimoto, M. Uehara, and K. Tsunoda, Electrochem. Commun., 2008, 10, 1351.

9. H. Takiguchi, T. Odake, M. Ozaki, T. Umemura, and K. Tsunoda, Appl. Spectrosc., 2003, 57, 1039.

10. H. Takiguchi, T. Odake, T. Umemura, H. Hotta, and K. Tsunoda, Anal. Sci., 2005, 21, 1269.

11. H. Takiguchi, S. Asanuma, H. Hotta, T. Odake, and K. Tsunoda, in Proceedings of $\mu$-TAS 2006, 2006, 1318.

12. H. Murata, J. Kamiyama, S. Asanuma, K. Sato, K. Tsunoda, H. Hotta, and Y. Sugii, in Proceedings of $\mu$-TAS 2012, 2012, 1785.

13. J. Kamiyama, S. Asanuma, H. Murata, Y. Sugii, H. Hotta, K. Sato, and K. Tsunoda, Appl. Spectrosc., 2013, 67, 1479.

14. D. B. Wolfe, R. S. Conroy, P. Garstecki, M. A. Fischbach, K. E. Paul, and G. M. Whitesides, Proc. Natl. Acad. Sci. U. S. A., 2004, 101, 12438.

15. B. T. Mayers, D. V. Vezenov, V. I. Vullev, and G. M. Whitesides, Anal. Chem., 2005, 77, 1310.

16. X. C. Li, J. Wu, A. Q. Liu, Z. G. Li, Y. C. Soew, H. J. Huang, K. Xu, and J. T. Lin, Appl. Phys. Lett., 2008, 93, 193901.

17. K. S. Lee, S. B. Kim, K. H. Lee, H. J. Sung, and S. S. Kim, Appl. Phys. Lett., 2010, 97, 021109. 
18. J. M. Lim, J. Urbanski, J. H. Choi, T. Thorsen, and S. M. Yang, Anal. Chem., 2011, 83, 585.

19. X.-D. Fan and I. M. White, Nature Photonics, 2011, 5, 591.

20. K. S. Lee, S. Y. Yoon, K. H. Lee, S. B. Kim, H. J. Sung, and S. S. Kim, Opt. Express, 2012, 20, 17348.

21. S.-K. Fan, H.-P. Lee, C.-C. Chien, Y.-W. Lu, Y. Chiu, and F.-Y. Lin, Lab Chip, 2016, 16, 847.

22. H. Watarai and Y. Saitoh, Chem. Lett., 1995, 283.

23. K. Fujiwara and H. Watarai, Langmuir, 2003, 19, 2658.

24. K. Fujiwara, S. Wada, H. Monjushiro, and H. Watarai, Langmuir, 2006, 22, 2482.

25. H. Yui, Y. Ikezoe, and T. Sawada, Anal. Sci., 2004, 20, 1501.

26. T. Tokimoto, S. Tsukahara, and H. Watarai, Chem. Lett.,
2001, 204.

27. T. Tokimoto, S. Tsukahara, and H. Watarai, Langmuir, 2005, 21, 1299.

28. M. Tabata, Y.-G. Wu, T. Charoenraks, and S. S. Samaratunga, Bull. Chem. Soc. Jpn., 2006, 79, 1742.

29. S. Niwayama, J. Org. Chem., 2000, 65, 5834.

30. A. Hibara, M. Nonaka, M. Tokeshi, and T. Kitamori, J. Am. Chem. Soc., 2003, 125, 14954.

31. A. Aota, A. Hibara, Y. Sugii, and T. Kitamori, Anal. Sci., 2012, 28, 9 .

32. M. Andujar-Sanchez, A. Cámara-Artigas, and V. Jara-Perez, J. Chem. Thermodynamics, 2010, 42, 337.

33. D. G. Leaist, K. MacEwan, A. Stefan, and M. Zamari, $J$. Chem. Eng. Data, 2000, 45, 815. 